\title{
Comprehensive analysis of current research trends in energy storage technologies
}

\author{
Surender Reddy Salkuti, Sravanthi Pagidipala, Seong-Cheol Kim \\ Department of Railroad and Electrical Engineering, Woosong University, Daejeon, Republic of Korea
}

\begin{tabular}{l} 
Article Info \\
\hline Article history: \\
Received Apr 17, 2021 \\
Revised Oct 22, 2021 \\
Accepted Oct 25, 2021 \\
\hline
\end{tabular}

\section{Keywords:}

Chemical energy storage

Energy storage

Frequency regulation

Green energy

Kinetic energy

Non-chemical energy storage

\begin{abstract}
This paper addresses the comprehensive analysis of various energy storage technologies, i.e., electrochemical and non-electrochemical storage systems by considering their storage methods, environmental impact, operations, costs, and their importance and applications. These storage technologies will help to reduce the energy shortage. There has been a significant deployment of storage systems in power grids throughout the world. The characteristics of storage systems such as the ability to act both as generation and load, fast response time, and high ramp rate. Make them promising options for the system operators to reduce the peak demand, and facilitate renewable energy integration. Various new trends in energy depict the ways this generated energy could be stored and harnessed. With the recent integration of renewable energy, it is important to store the energy and it is combined to help the green energy demand. The integration of renewable energy into the power grid has increased reliability, efficiency, and stability. Adding the energy component will further enhance the capabilities of the grid. This paper also recommends an optimal storage technique from various available storage technologies.
\end{abstract}

This is an open access article under the CC BY-SA license.

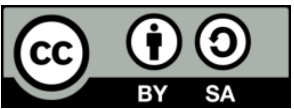

\section{Corresponding Author:}

Seong-Cheol Kim

Department of Railroad and Electrical Engineering

Woosong University

Jayang-dong, Dong-gu, Daejeon, Republic of Korea

Email:kmin@wsu.ac.kr

\section{INTRODUCTION}

Renewable energy (RE) is abundant in nature, cost-effective and environmentally friendly nature helps it as a way to solve the energy shortage. There is an urgent need to decrease the deleterious consequence of the use of fossil fuels. The uses of RE can provide an explicit solution to address this issue. $\mathrm{RE}$ is economical, environmentally friendly and sustainable. Therefore, all countries are investing plans and investments to improve renewable energy source (RES) utilization as much as possible. The RE sources such as solar photovoltaic (PV), wind, geothermal and wave energy are extensively studied and implemented. However, without combining with energy storages, these RE sources cannot be used as long-term electrical solutions. The solar and wind energy variations are influenced by the time of day, weather patterns and installation site. For standalone and grid interactive systems, storage systems are often used for smooth power output from RE sources. Energy storage will serve as energy backup, which stores energy during excess power consumption and releasing it during the power deficit. Energy storage can be defined as the techniques of using devices or physical media to store electrical energy that is intended to be utilized at a later time. Energy storage elements store the energy by accumulating it [1]. There are different types of energy: potential energy (for example gravitational, chemical, electrical, and mechanical), or kinetic energy 
(for example thermal energy), and each form of energy is stored by a specific storage device. Batteries are utilized to store the convertible chemical energy, hydroelectric dam stores the energy in a reservoir as gravitational positional energy. Others storage devices like ice storage tanks are used to store thermal energy at night time to meet the peak load for cooling [2], [3]. There are several fluctuations of energy supply and demand due to the daily societal activities in the 24-hour day-cycle. As a result, there are periods of energy surpluses and deficits. This can be handled by using energy storage technologies. Having a storage system enables energy to be stored during periods of surpluses and supply energy during peak demands. Energy storage components are used to perform several functions such as grid stabilization, frequency regulation, grid operational support, and voltage support [4].

Mechanical energy storage systems include pumped hydroelectric energy storage (PHES), compressed air energy storage (CAES), and flywheel energy storage. Chemical energy storage includes hydrogen. Electrochemical ES includes traditional batteries (Nickel Cadmium (NiCd), Lead-acid (PbA), Lithium-ion (Liion)), flow batteries (Vanadium redox (VR), and Zinc Bromine ( $\mathrm{ZnBr})$ ), and high-temperature batteries (Sodium sulfur (NaS) and ZEBRA). Electric filed batteries include magnetic field batteries include superconducting magnetic coil (SMES), double-layer capacitor, and thermal batteries include molten salt [5].

The role of energy storage systems in the development of smart grids has been presented in [6]. Zhang et al. [7] presents an overview of hybrid energy storage systems (ESSs) focusing on battery-supercapacitor hybrids, covering different aspects in electric vehicles and smart grid applications. Aktas et al. [8] presents a hybrid ESSs consisting of high energy and power density storage battery bank and ultracapacitor unit for sudden variation of load demand. A new hybrid ESS composed of CAES cycle as mechanical storage and amine-assisted $\mathrm{CO}_{2}$ capture cycle as chemical energy storage has been proposed in [9]. Rahman et al. [10] reviews the techno-economic and life cycle assessments of ESSs. An integrated planning approach has been proposed in [11] which optimally determines the locations and capacities of interconnected Internet data centers and battery ESSs in a smart grid. The latest trends in energy storage applications, both cradles, and grave along with their possible prospects are discussed in [12]. A new type of multi-time scale cold energy storage system consisting of heat pipe-based natural ice storage subsystem and a dual-operation chiller for buildings to enhance their energy flexibility has been described in [13].

This paper focuses on not only the different types of energy storage but also the comprehensive review of various storage technologies to be used in the renewable energy sources (RESs) connected to the utility grid. Storage batteries are selected based on the battery type, temperature and physical requirements, cycling schedule, working life, charge/discharge cycle, safety and reliability, electrochemical system, voltage and load current profile, maintenance, and price. This paper also analyzes each energy storage type and compares them to each other. Some of the current technologies that exist for energy storage include batteries, flywheels, compressed air, electrochemical capacitors, and pumped hydro. Energy storage systems (ESSs) are broadly classified into electrochemical and non-electrochemical energy storage and they are described in this paper.

\section{ELECTROCHEMICAL ENERGY STORAGE SYSTEMS (ESSs)}

Electrochemical ESSs include lithium-ion, lead-acid, sodium-sulfur, nickel-metal hydride, nickelcadmium, and flow batteries [14]-[16]. One of the most widely used energy storage system is the battery. Its stores electrical energy in the form of chemical structure. Battery has high energy density device, it means to support power to the system for longer time. To process electrochemical reactions inside the cell, a certain amount of time is needed. Thus, it is not support for sudden and fast changing of PV generation and load demand. Due to its high internal resistance, their internal losses are high. During charging/discharging of battery its internal structural integrity changes. The cycle life of battery determined by its charge/discharge rate. Even though batteries have drawbacks like low power density and life cycle, they are most dominant in renewable power generation and electric vehicle applications.

Rechargeable batteries include lithium-ion, lead-acid, Vanadium Redox, sodium-sulfur, nickel-metal hydride, nickel-cadmium, and Zinc Bromine [17]. Other new battery technologies such as sodium-sulfur and sodium nickel chloride have failed to deliver on their promises as yet although the technical performance achieved in ongoing research is quite remarkable. The life of a battery depends on the temperature where the battery is being stored. Lower temperature can reduce the rate of side reactions, although some batteries can be damaged by frizzing temperatures.

Non-rechargeable/primary batteries are for single use only and they include zinc-chloride, zinccarbon, silver-oxide, and alkaline. Rechargeable/secondary batteries are capable of performing multiple charging and discharging cycles [18]-[22]. Batteries are made by using the positive electrode, negative electrode, electrode, and separator. The internal parts of a rechargeable battery may be corroded by the chemical reactions and fail. This corrosion may also slowly convert the active materials into inactive 
materials. During the charging process, electrical energy from the grid is stored in the battery in the form of chemical energy, whereas during the process of discharging the chemical energy from the battery is injected into the grid in the form of electrical energy. It is important to mention that the life of every battery can be extended by about $5 \%$, and to extend the life of a battery one should store the batteries at low temperature as it is indicated either on the batteries themselves or their boxes [23].

One of the main environmental concerns in our world today regarding batteries is a toxic metal. Used batteries often involve hazardous chemicals and contribute to electronic waste which is a huge problem to our environment. It is important to mention how the battery storage techniques are being used in the technology of renewable energy. In the wind energy system, the batteries are used to store energy to be used during peak hours, especially at night [24]-[26]. The capacity function of the current of a battery $\left(Q_{\max }(I)\right)$ can be expressed as (1).

$$
Q_{\max }(I)=\frac{k c T Q_{\max }^{0}}{1-e^{-k T}+c\left(k T-1+e^{-k T}\right)}
$$

Where $c$ the ratio of available charge capacity to total capacity, $k$ is the rate constant and $Q_{\max }^{0}$ is the maximum capacity of the battery [27]-[29]. The lifetime model of battery uses a double exponential curve fit to data characterizing cycles to failures versus cycle depth, and it is modeled using [30],

$$
C_{F}=a_{1}+a_{2} e^{-a_{3} R}+a_{4} e^{-a_{5} R}
$$

where $a_{i}$ is the fitting constants, $C_{F}$ is cycles to failures and $R$ is the cycle range.

\subsection{Lithium-ion (Li-ion) battery}

It is composed of an electrode (positive electrode is metal oxide and the negative electrode is carbon) and an electrolyte (i.e., lithium salt). Li-ion batteries travel among the electrodes during the chemical reactions of charging and discharging. The positive electrode reaction is represented by [31], [32].

$$
\mathrm{Li}^{+}+\mathrm{CoO}_{2}+e^{-} \leftarrow \rightarrow \mathrm{LiCoO}_{2}
$$

The negative electrode reaction is represented by,

$$
\mathrm{LiC}_{6} \leftarrow \rightarrow \mathrm{C}_{6}+\mathrm{Li}^{+}+\mathrm{e}^{-}
$$

The overall reaction is represented by,

$$
\mathrm{LiC}_{6}+\mathrm{CoO}_{2} \leftarrow \rightarrow \mathrm{C}_{6}+\mathrm{LiCoO}_{2}
$$

These batteries are used in automobiles, consumer electronics, and utility applications [33]-[35]. Liion batteries do not pose a huge environmental impact when compared to lead-acid batteries. The main advantages of Li-ion batteries are their high energy, power densities, capacity, and high efficiency, long life, low internal resistance, and self-discharge. However, the disadvantages are related to the Li-ion batteries include high cost, requires power electronics, safety issues, possess relatively high internal resistance, and impossible to charge at low temperatures [36]. The cost of a Li-ion battery is $0.47 \$ / \mathrm{Wh}$. There hasn't been any recent breakthrough with this technology apart from the research to improve the power density, costs, recharge cycles, and safety of these batteries.

\subsection{Lead acid batteries}

These are some of the oldest, efficient, and widely used batteries. The oldest battery technology is the lead acid battery. Gaston Plante was the first to study how to extract current from a pair of lead plates immersed in sulphuric acid in 1859. To meet several requirements, the different design and models of leadacid batteries have been proposed. However, the basic fundamental electro chemical lead-acid battery remains same over 150 years. It is a popular rechargeable battery used in microgrids and electric vehicles. They are found in several applications including cars (i.e., automobiles), and electronic devices (watches, uninterruptible power supply (UPS)), Substation reserve power, and communication systems. The electrolyte in lead-acid batteries participates in the chemical reactions during the charging/discharging. By adding carbon-based materials to the negative electrode reduces sulfation and increases the conductivity [37]-[39]. The average cost of this battery is about $0.174 \$ / \mathrm{W}$. The main advantages of these batteries are less expensive, matured technology, high reliability and discharge power, low self-discharge rate, and no memory effect. However, the disadvantages include a slow charging rate and low specific energy. 


\subsection{Nickel-based batteries}

These are classified into nickel cadmium (NiCd) batteries and Nickel Metal Hydride (NiMH) Batteries, and they are presented next.

\subsubsection{Nickel cadmium $(\mathrm{NiCd})$ batteries}

$\mathrm{NiCd}$ battery consists of a positive electrode (i.e., Nickel oxide hydroxide $(\mathrm{NiO}(\mathrm{OH}))$ and a negative electrode (i.e., metallic cadmium $(\mathrm{Cd})$ ), electrolyte, and a separator. The negative electrode reaction during the discharge is represented by [40].

$$
\mathrm{Cd}+2 \mathrm{OH}^{-} \rightarrow \mathrm{Cd}(\mathrm{OH})_{2}+2 e^{-}
$$

The positive electrode reaction during the discharge is represented by,

$$
2 \mathrm{NiO}(\mathrm{OH})+2 \mathrm{H}_{2} \mathrm{O}+2 e^{-} \rightarrow 2 \mathrm{Ni}(\mathrm{OH})_{2}+2 \mathrm{OH}^{-}
$$

The overall reaction during the discharge is represented by (8).

$$
2 \mathrm{NiO}(\mathrm{OH})+\mathrm{Cd}+\mathrm{H}_{2} \mathrm{O} \rightarrow 2 \mathrm{Ni}(\mathrm{OH})_{2}+\mathrm{Cd}(\mathrm{OH})_{2}
$$

The technology behind the NiCd batteries is quite old and there has not been a recent breakthrough [41], [42]. Because of this toxicity, the NiCd batteries are replaced by NiMH batteries. The main advantages of these batteries are high charge/discharge cycles and profitability, operation at low temperatures, and fast charging. Whereas the disadvantages are low cell voltage and specific energy, high self-discharge, and the toxicity of Cadmium.

\subsubsection{Nickel metal hydride (NiMH) batteries}

The main features of NiMH batteries include its higher capacity, better cycle life than lead-acid batteries, higher energy density, no problems with electrode toxicity and it is less prone to memory effect when compared to NiCd batteries. Applications of these batteries are consumer electronics and utility/telecom backup. The cost of a NiMH battery is $0.99 \$ / \mathrm{Wh}$ and it is a matured technology [43]. The disadvantages of NiMH batteries are limited long-term potential for cost reductions, more expensive than lead-acid batteries, high degree of self-discharge, low cell voltage, very low coulombic efficiency and it requires complex charging algorithm.

\subsection{Sodium-sulfur $(\mathrm{NaS})$ batteries}

This battery consists of molten Sulphur $(\mathrm{S})$ as the positive electrode and molten sodium (Na) as the negative electrode [44]. The positive electrode reaction is represented by (9).

$$
x S+2 e^{-} \leftarrow S_{x}^{-2}
$$

The negative electrode reaction is represented by (10).

$$
2 N a \leftarrow \rightarrow 2 N a^{+}+2 e^{-}
$$

The overall reaction is represented by (11).

$$
2 \mathrm{Na}+x S \leftarrow \rightarrow N a_{2} S_{x}
$$

During the discharging process, the $\mathrm{Na}$ passes from negative electrode to positive one, and sodium polysulfide $\left(\mathrm{Na}_{2} \mathrm{~S}_{x}\right)$ is formed at the operating temperature (i.e., (300-350) ${ }^{\circ} \mathrm{C}$. This process is reversed during the charging. The life span of this battery is between (10-15) years depending on the depth of discharge and frequency of use [45]. The advantages of these batteries include higher power density and energy, long cycle life, very low self-discharge, higher rated capacity, efficiency, and recyclability. The disadvantages are quite expensive and high operating costs and produce high temperatures (i.e., safety issues).

\subsection{Vanadium redox (VR) flow batteries}

The redox cell works on the principle of reduction-oxidation. This battery uses vanadium ions in 4 oxidation states to store the chemical potential energy. The positive electrode reaction is represented by (12). 


$$
\mathrm{VO}^{2+}+\mathrm{H}_{2} \mathrm{O} \leftarrow \mathrm{VO}_{2}^{+}+2 \mathrm{H}^{+}+e^{-}
$$

The negative electrode reaction is represented by (13).

$$
V^{3+}+e^{-} \leftarrow \rightarrow V^{2+}
$$

The liquid electrolyte of metallic salts is pumped through the core, which consists of negative and positive electrodes, and they are separated by membrane [46]. Electricity is generated by ion exchange between anode and cathode. The operating temperature of this battery is $(10-40){ }^{\circ} \mathrm{C}$. The main advantages of VR batteries include the high energy, current, and power densities, quick response times, scalable for large applications, no harmful emissions, easily upgradeable, long cycle life, independent energy and power sizing, and higher roundtrip efficiency. But the main disadvantages include higher cost, construction complexity, and efficiency losses [47]. VR batteries are used in peak shaving for transmission and distribution, power quality, reliability, backup power, and small load-leveling applications such as frequency regulation, spinning reserves, and voltage support.

\subsection{Supercapacitor}

Supercapacitors (SCs) also referred to as ultracapacitors or electric double-layer capacitors are electrochemical components that have a relatively high energy density. In 1978, they produced commercial SCs and used for computer memory backup in consumable electronics. Several products have been modified during the course of the manufacturing process. The SCs with capacitances ranging from 1000 to $5000 \mathrm{~F}$ and energy densities ranging from 3.5 to $4.9 \mathrm{Wh} / \mathrm{kg}$ is commercially available in the 21 st century. The SCs are low voltage range with high capacitance value compared to electrolytic capacitance. It reduces the gap between the battery and the electrolytic capacitor system. The major advantages of SC are high power density and longer life cycle. During charging/discharging process, there no change of internal structural integrity in SC. The only drawback of SC is that it has a higher rate of self-discharge. The self-discharge rate is around $20 \%$ of stored energy in a day even in no load condition.

When compared to regular conventional capacitors, supercapacitors have a high energy density this is generally hundreds of times greater than regular capacitors. When the supercapacitors are operated singly can only store so much power [48]. Supercapacitors' prices are dropping due to the different researches that are being conducted to improve their performance. Applications include emergency bridging power, power quality, fluctuation smoothing, and automotive where an ultra-battery is combined with a supercapacitor in one unit for creating the battery of electric vehicle (EV) last longer, cost less, and be more powerful.

The advantages of supercapacitors are their long life, being environmentally friendly, and they have little degradation over hundreds of thousands of charge cycles. These batteries can be recharged quickly, have high power density, low cost per cycle, high efficiency and specific power, improved safety, and long life. However, the main disadvantages include a lower amount of energy stored per unit, high self-discharge, high dielectric absorption, expensive, and low maximum voltage. To get higher voltages, one must use series connections, which may require balancing the system.

\section{NON-CHEMICAL ENERGY STORAGE}

\subsection{Flywheel energy storage}

The flywheel stores the kinetic energy (KE) in rotating inertia. A Brushless DC machine is most suitable for use in the flywheel. A flywheel with a moment of inertia $(J)$ rotating at an angular velocity of $(\omega)$ stores the energy $(E)$, and it is expressed as (14) [49].

$$
E=\frac{1}{2} J \omega^{2}
$$

For any allowable rotor tip velocity $(v)$, the maximum energy that can be stored is given by (15).

$$
E_{\text {max }}=k v^{2}\left[1+\left(\frac{r_{1}}{r_{2}}\right)^{2}\right]
$$

Where $r_{i}$ is the inner radius, $r_{o}$ is the outer radius, and $k$ is the proportional constant. This storage system can be used for power quality, frequency regulation, fluctuation smoothing, and emergency bridging power [50]. Flywheel energy storage systems have quick recharge, high power density, high cycle life, independent power and energy sizing, fast response time as it requires only a very short recharge time, handles high power 
levels, and independent of changes in temperatures. However, the main disadvantages include large power standby losses, potentially dangerous during the failure modes, low energy density, short energy storage time, and gyroscopic effects.

\subsection{Compressed air energy storage (CAES) system}

This CAES system is used to store energy to be used during peak hours. The technique consists of compressing air to generate heat. The heat is then stored to be used during peak hours. These three types of air storage can be used in CAES and they are adiabatic, diabatic, or isothermic. In this storage system, compressed air is used to generate electricity. The compression can be expressed by using [50],

$$
P_{c}=\frac{1}{n_{c}} m C_{p}\left[\left(\frac{p_{2}}{p_{1}}\right)^{\frac{k-1}{k}}-1\right]
$$

where $m$ is the mass flow rate of the air, $n_{c}$ is the overall efficiency of the compressor, $P_{c}$ the input power to the compressor, $\mathrm{k}$ is specific heat ratio of air $\left(\mathrm{C}_{\mathrm{p}} / \mathrm{C}_{\mathrm{v}}\right), p_{1}$ and $p_{2}$ are the pressure at the inlet and outlet of the compressor. The compressed air follows ideal gas laws and they are given by (17).

$$
p V=n R T
$$

Where $\mathrm{n}$ is the amount of gas (mol), $\mathrm{V}$ is volume, $\mathrm{p}$ is absolute volume, $\mathrm{T}$ is absolute temperature, and $\mathrm{R}$ is the ideal gas constant. This produces the work/energy to drive the turbine, and it is given by (18).

$$
W=p_{B} p_{A} \ln \frac{p_{A}}{p_{B}}
$$

CAES plants have a relatively low start-up time. Usually within seconds for regular starts, or a few minutes for a cold start [51]. CAES system has low efficiency. Some demonstrations have managed to show efficiencies as high as $75 \%$, however other demonstrations have shown efficiencies as low as $40 \%$. The reluctance of a lot of utility companies to focus on this method of storage indicates a consensus with the lowefficiency values. The CAES systems can be used for frequency regulation, energy arbitrage, and auxiliary services. The CAES system can be easily scaled, capable of producing up to a few megawatts of power.

\subsection{Pumped hydroelectric energy storage (PHES)}

The PHES system operates by pumping the water from a reservoir. The reservoir is usually located at a lower location. The water is pumped to a higher elevation during times of lower demand of electricity and is released to the consumers during peak demand for energy. This principle is the same as the one in the hydroelectric station. The efficiency of the PHES system is between 755 to $85 \%$, and its size varies from 200 MW to $2000 \mathrm{MW}$. It converts the potential energy of water into electrical power. The potential energy is given by [51].

$$
\mathrm{E}=\mathrm{mgh}
$$

The hydro-electric power is given by (20).

$$
P=\rho \varphi g h=h r g k
$$

Where $\mathrm{E}$ is energy, $\mathrm{m}$ is mass, $\mathrm{P}$ is hydroelectric power, $\rho$ is the density of water, $\mathrm{g}$ is the acceleration due to gravity, $\mathrm{k}$ is the coefficient of efficiency, and $\varphi$ is the rate of fluid flow. The advantages of this storage system are environmentally safe, as they produce no air pollutants, relatively efficient form of energy storage, efficiency typically is about $80 \%$, is a self-sufficient method of storage, has huge energy, and power capacity. However, this storage system has a large scale only, long construction time, is expensive to site and build, geographically limited and the generator must be below sea level [52]. The main applications are frequency regulation, energy arbitrage, and auxiliary services. Finally, advances are currently being made into the utilization of wind turbines or solar power to drive the pumps directly and when executed, could prove a huge cost saver in this method.

\section{CONCLUSION}

This paper presents various available electrical energy storage devices and their characteristics. 
These devices are used for grid stabilization, grid operational support, frequency regulation, voltage support, and load shifting, and they will ensure a sustainable and efficient grid that would help both the customer and utility supplier to save energy costs. The objective of this paper is to study different ways of storing energy. From this paper, it can be concluded that a flywheel storage system is the most efficient form of energy storage. In addition to their stability, flywheels last over a lifetime and are very friendly to the environment as long as the circuit boards are recycled. Also, with flywheels, utility companies can store sufficient energy to be used during peak hours. Unlike flywheels, batteries are problematic to the environment. Due to the chemical, they contain wasted batteries that can penetrate and destroy the environment. Supercapacitors have almost the same advantages as flywheels. Supercapacitors have high reliability, moderate maintenance, and has low operating costs.

\section{ACKNOWLEDGEMENT}

This research work was funded by "Woosong University’s Academic Research Funding - 2021”.

\section{REFERENCES}

[1] S. Al-Hallaj, S. Wilke, and B. Schweitzer, "Energy Storage Systems for Smart Grid Applications," Water, Energy \& Food Sustainability in the Middle East. Springer, Cham, 2017, doi: 10.1007/978-3-319-48920-9_8.

[2] A. D. Georgakarakos, M. Mayfield, and E. A. Hathway, "Battery Storage Systems in Smart Grid Optimised Buildings," Energy Procedia, vol. 151, pp. 23-30, Oct. 2018, doi: 10.1016/j.egypro.2018.09.022.

[3] S. R. Salkuti, "Comparative analysis of electrochemical energy storage technologies for smart grid," TELKOMNIKA (Telecommunication, Computing, Electronics and Control), vol. 18, no. 4, pp. 2118-2124, Aug. 2020, doi: 10.12928/telkomnika.v18i4.14039.

[4] M. Cheng, S. S. Sami, and J. Wu, "Virtual Energy Storage System for Smart Grids," Energy Procedia, vol. 88, pp. 436-442, Jun. 2016, doi: 10.1016/j.egypro.2016.06.021.

[5] S. R. Salkuti, "Energy Storage Technologies for Smart Grid: A Comprehensive Review," Majlesi Journal of Electrical Engineering, vol. 14, no. 1, pp. 39-48, Mar. 2020.

[6] D. Kolokotsa et al., "On the integration of the energy storage in smart grids: Technologies and applications," Energy Storage, vol. 1, no. 1, Feb. 2019, doi: 10.1002/est2.50.

[7] L. Zhang et al., "Hybrid electrochemical energy storage systems: An overview for smart grid and electrified vehicle applications," Renewable and Sustainable Energy Reviews, 2020, doi: 10.1016/j.rser.2020.110581.

[8] A. Aktas, K. Erhan, S. Özdemir, and E. Özdemir, "Dynamic energy management for photovoltaic power system including hybrid energy storage in smart grid applications," Energy, vol. 162, pp. 72-82, Nov. 2018, doi: 10.1016/j.energy.2018.08.016.

[9] M. Mehrpooya and P. Pakzad, "Introducing a hybrid mechanical - Chemical energy storage system: Process development and energy/exergy analysis," Energy Conversion and Management, vol. 211, May 2020, doi: 10.1016/j.enconman.2020.112784.

[10] Md. M. Rahman, A. O. Oni, E. Gemechu, and A. Kumar, "Assessment of energy storage technologies: A review," Energy Conversion and Management, vol. 223, Nov. 2020, doi: 10.1016/j.enconman.2020.113295.

[11] C. Guo, F. Luo, Z. Cai, Z. Y. Dong, and R. Zhang, "Integrated planning of internet data centers and battery energy storage systems in smart grids," Applied Energy, vol. 281, Jan. 2021, doi: 10.1016/j.apenergy.2020.116093.

[12] A. G. Olabi, C. Onumaegbu, T. Wilberforce, M. Ramadan, M. A. Abdelkareem, and A. H. Al-Alami, "Critical review of energy storage systems," Energy, vol. 214, Jan. 2021, doi: 10.1016/j.energy.2020.118987.

[13] C. Yan, F. Wang, Y. Pan, K. Shan, and R. Kosonen, "A multi-timescale cold storage system within energy flexible buildings for power balance management of smart grids," Renewable Energy, vol. 161, pp. 626-634, Dec. 2020, doi: 10.1016/j.renene.2020.07.079.

[14] S. Ponnuru, R.A. Kumar, and N. M. J. Swaroopan, "GWO-based MPPT controller for grid connected Solid oxide fuel cell with high step up DC-DC converter," Indonesian Journal of Electrical Engineering and Computer Science, vol. 23, no. 3, pp. 1794-1803, 2021, doi: 10.11591/ijeecs.v23.i3.pp1794-1803.

[15] M. Zadehbagheri, T. Sutikno, and R. Ildarabadi, "Using y-source network as a connector between turbine and network in the structure of variable speed wind turbine," International Journal of Power Electronics and Drive Systems, vol. 12, no. 3, pp. 1644-1658, 2021, doi: 10.11591/ijpeds.v12.i3.pp1644-1658.

[16] Z. Bououchma and J. Sabor, "Online diagnosis of supercapacitors using extended kalman filter combined with pid corrector," International Journal of Power Electronics and Drive Systems, vol. 12, no. 3, pp. 1521-1534, 2021, doi: 10.11591/ijpeds.v12.i3.pp1521-1534.

[17] A. Hariyadi, A. Nugroho, and Suwarno, "The origin of cycle life degradation of a lead-acid battery under constant voltage charging," International Journal of Power Electronics and Drive Systems, vol. 12, no. 2, pp. 986-993, 2021, doi: 10.11591/ijpeds.v12.i2.pp986-993.

[18] A. Saavedra, N. A. Galvis, M. Castaneda, S. Zapata, F. Mesa, and A. J. Aristizábal, "Feasibility of using photovoltaic solar energy for water treatment plants," International Journal of Electrical and Computer Engineering, vol. 11, no. 3, pp. 1962-1968, 2021, doi: 10.11591/ijece.v11i3.pp1962-1968. 
[19] S. R. Salkuti and C. M. Jung, "Overview of Energy Storage Technologies: A Techno-Economic Comparison," International Journal of Applied Engineering Research, vol. 12, no. 22, pp. 12872-12879, Nov. 2017.

[20] M. C. Such and C. Hill, "Battery energy storage and wind energy integrated into the Smart Grid," IEEE PES Innovative Smart Grid Technologies, Washington, DC, pp. 1-4, 2012, doi: 10.1109/ISGT.2012.6175772.

[21] T. Yang, Z. Han, F. Yang, Y. Liang, J. Gao, and X. Ji, "Coordinated Optimal Configuration Method of Hybrid Energy Storage Systems in Energy Internet System,” IEEE Innovative Smart Grid Technologies - Asia (ISGT Asia), Chengdu, China, 2019, pp. 1515-1519, doi: 10.1109/ISGT-Asia.2019.8881807.

[22] M. S. A. Mustazal, M. A. M Ariff, and S. N. Ramli, "An extensive review of energy storage system for the residential renewable energy system," Indonesian Journal of Electrical Engineering and Computer Science, vol. 18, no. 1, pp. 242-250, 2019, doi: 10.11591/ijeecs.v18.i1.pp242-250.

[23] D. Selvabharathi and N. Muruganantham, "Battery health and performance monitoring system: A closer look at state of health $(\mathrm{SoH})$ assessment methods of a lead-acid battery," Indonesian Journal of Electrical Engineering and Computer Science, vol. 18, no. 1, pp. 261-267, 2019, doi: 10.11591/ijeecs.v18.i1.pp261-267.

[24] T. Pangaribowo, W. M. Utomo, A. A. Bakar, and D. S. Khaerudini, "Battery charging and discharging control of a hybrid energy system using microcontroller," Indonesian Journal of Electrical Engineering and Computer Science, vol. 17, no. 2, pp. 575-582, 2019, doi: 10.11591/ijeecs.v17.i2.pp575-582.

[25] K. Kroics, O. Husev, K. Tytelmaier, J. Zakis, and O. Veligorskyi, "An overview of bidirectional AC-DC grid connected converter topologies for low voltage battery integration," International Journal of Power Electronics and Drive Systems, vol. 9, no. 3, pp. 1223-1239, 2018, doi: 10.11591/ijpeds.v9.i3.pp1223-1239.

[26] J. A. Momoh, "Energy Processing and Smart Grid," Wiley-IEEE Press, Jul. 2018, doi: 10.1002/9781119521129.

[27] A. A. Jamali, N. M. Nor, and T. Ibrahim, "Energy storage systems and their sizing techniques in power system - A review," IEEE Conference on Energy Conversion, Johor Bahru, 2015, pp. 215-220, doi: 10.1109/CENCON.2015.7409542.

[28] S. O. Showers and A. K. Raji, "Benefits and Challenges of Energy Storage Technologies in High Penetration Renewable Energy Power Systems," IEEE PES/IAS PowerAfrica, Abuja, Nigeria, pp. 209-214, 2019, doi: 10.1109/PowerAfrica.2019.8928644.

[29] F. Nadeem, S. M. S. Hussain, P. K. Tiwari, A. K. Goswami, and T. S. Ustun, "Review of Smart and Innovative Energy Storage Systems," International Conference on Vision Towards Emerging Trends in Communication and Networking, Vellore, India, 2019, pp. 1-6, doi: 10.1109/ViTECoN.2019.8899397.

[30] S. Nagaraj, R. Ranihemamalini, and L. Rajaji, "Design and analysis of controllers for high voltage gain dc-dc converter for pv panel," International Journal of Power Electronics and Drive Systems, vol. 11, no. 2, pp. 594-604, 2020, doi: 10.11591/ijpeds.v11.i2.pp594-604.

[31] S. Nagaraj, R. Ranihemamalini, and L. Rajaji, "Performance enhancement of DC/DC converters for solar powered EV," International Journal of Electrical and Computer Engineering, vol. 10, no. 4, pp. 3423-3430, 2020, doi: 10.11591/ijece.v10i4.pp3423-3430.

[32] N. M. L. Tan, A. K. Ramasamy, V. K. Ramachandaramurthy, M. Marsadek, M. R. Othman, and I. Ariffin, "Utilityscale photovoltaic generators: A review on trends, grid code requirements and challenges," Indonesian Journal of Electrical Engineering and Computer Science, vol. 18, no. 2, pp. 573-585, 2020, doi: 10.11591/ijeecs.v18.i2.pp573-585.

[33] B. V. Rajanna and M. K. Kumar, "Comparison of one and two time constant models for lithium ion battery," International Journal of Electrical and Computer Engineering, vol. 10, no. 1, pp. 670-680, 2020, doi: 10.11591/ijece.v10i1.pp670-680.

[34] Y. Boujoudar, H. Elmoussaoui, and T. Lamhamdi, "Lithium-ion batteries modeling and state of charge estimation using artificial neural network," International Journal of Electrical and Computer Engineering, vol. 9, no. 5, pp. 3415-3422, 2019, doi: 10.11591/ijece.v9i5.pp3415-3422.

[35] S. R. Salkuti, "Large scale electricity storage technology options for smart grid," International Journal of Engineering \& Technology, vol. 7, no. 2, pp. 635-639, Apr. 2018, doi: 10.14419/ijet.v7i2.11395.

[36] F. Nadeem, S. M. S. Hussain, P. K. Tiwari, A. K. Goswami, and T. S. Ustun, "Comparative Review of Energy Storage Systems, Their Roles, and Impacts on Future Power Systems,” IEEE Access, vol. 7, pp. 4555-4585, 2019, doi: 10.1109/ACCESS.2018.2888497.

[37] T. M. Gür, "Review of electrical energy storage technologies, materials and systems: challenges and prospects for large-scale grid storage," Energy and Environmental Science, vol. 11, pp. 2696-2767, 2018, doi: 10.1039/C8EE01419A.

[38] S. R. Salkuti and C. M. Jung, "Comparative analysis of storage techniques for a grid with renewable energy sources," International Journal of Engineering \& Technology, vol. 7, no. 3, pp. 970-976, May 2018, doi: 10.14419/ijet.v7i3.12728.

[39] A. A. K. Arani, G. B. Gharehpetian, and M. Abedi, "Review on Energy Storage Systems Control Methods in Microgrids," International Journal of Electrical Power \& Energy Systems, vol. 107, pp. 745-757, May 2019, doi: 10.1016/j.ijepes.2018.12.040.

[40] S. R. Salkuti, "Electrochemical batteries for smart grid applications," International Journal of Electrical and Computer Engineering, vol. 11, no. 3, pp. 1849-1856, 2021, doi: 10.11591/ijece.v11i3.pp1849-1856.

[41] J. Kumar, N. R. Parhyar, M. K. Panjwani, and D. Khan, "Design and performance analysis of PV grid-tied system with energy storage system," International Journal of Electrical and Computer Engineering, vol. 11, no. 2, pp. 1077-1085, 2021, doi: 10.11591/ijece.v11i2.pp1077-1085.

[42] A. M. Alsabari, M. K. Hassan, A. Cs, and R. Zafira, "Modeling and validation of lithium-ion battery with initial state of charge estimation," Indonesian Journal of Electrical Engineering and Computer Science, vol. 21, no. 3, pp. 1317-1331, 2021, doi: 10.11591/ijeecs.v21.i3.pp1317-1331. 
[43] P. Sharma, S. R. Salkuti, and S. C. Kim, "Energy audit: Types, scope, methodology and report structure," Indonesian Journal of Electrical Engineering and Computer Science, vol. 22, no. 1, pp. 45-52, 2021, doi: 10.11591/ijeecs.v22.i1.pp45-52.

[44] E. M. Laadissi, J. Khalfi, F. Belhora, C. Ennawaoui, and A. E. Ballouti, "Aging study of a lead-acid storage bank in a multi-source hybrid system," Indonesian Journal of Electrical Engineering and Computer Science, vol. 20, no. 3, pp. 1109-1117, 2020, doi: 10.11591/ijeecs.v20.i3.pp1109-1117.

[45] S. R. Salkuti, "Optimal Power Flow with Renewable Energy Resources including Storage," Electrical Engineering, vol. 99, no. 2, pp. 685-695, Jun. 2017, doi: 10.1007/s00202-016-0402-5.

[46] O. Krishan and S. Suhag, "An updated review of energy storage systems: Classification and applications in distributed generation power systems incorporating renewable energy resources," International Journal of Energy Research, vol. 43, no. 12, pp. 6171-6210, Oct. 2019, doi: 10.1002/er.4285.

[47] L. Yao, B. Yang, H. Cui, J. Zhang, J. Ye, and J. Xue, "Challenges and progresses of energy storage technology and its application in power systems," Journal of Modern Power Systems and Clean Energy, vol. 4, pp. 519-528, 2016, doi: 10.1007/s40565-016-0248-x.

[48] V. A. Boicea, "Energy Storage Technologies: The Past and the Present," Proceedings of the IEEE, vol. 102, no. 11, pp. 1777-1794, Nov. 2014, doi: 10.1109/JPROC.2014.2359545.

[49] V. Sandeep, S. Shastri, A. Sardar, and S. R. Salkuti, "Modeling of battery pack sizing for electric vehicles," International Journal of Power Electronics and Drive Systems, vol. 11, no. 4, pp. 1987-1994, 2020, doi: 10.11591/ijpeds.v11.i4.pp1987-1994.

[50] B. Amel, Z. Soraya, and C. Abdelkader, "Intelligent control of flywheel energy storage system associated with the wind generator for uninterrupted power supply," International Journal of Power Electronics and Drive Systems, vol. 11, no. 4, pp. 2062-2072, 2020, doi: 10.11591/ijpeds.v11.i4.pp2062-2072.

[51] L. Chen, T. Zheng, S. Mei, X. Xue, B. Liu, and Q. Lu, "Review and prospect of compressed air energy storage system," Journal of Modern Power Systems and Clean Energy, vol. 4, pp. 529-541, 2016, doi: 10.1007/s40565-016-0240-5.

[52] C. L. Nge, I. U. Ranaweera, O. M. Midtgård, and L. Norum, "A real-time energy management system for smart grid integrated photovoltaic generation with battery storage," Renewable Energy, vol. 130, pp. 774-785, Jan. 2019, doi: 10.1016/j.renene.2018.06.073. 